\title{
Object based classification for land cover using Sentinel-1A in Yogyakarta
}

\section{Adistina Lailia Fajar Dewi, Retnadi Heru Jatmiko}

Adistina Lailia Fajar Dewi, Retnadi Heru Jatmiko, "Object based classification for land cover using Sentinel-1A in Yogyakarta," Proc. SPIE 11311, Sixth Geoinformation Science Symposium, 113110S (21 November 2019); doi: $10.1117 / 12.2547314$

SPIE Event: Sixth Geoinformation Science Symposium, 2019, Yogyakarta, Indonesia 


\title{
Object Based Classification for Land Cover Mapping using Sentinel $-1 \mathrm{~A}$ in Yogyakarta
}

\author{
Retnadi Heru Jatmiko ${ }^{\text {a }}$, Adistina Lailia Fajar Dewi ${ }^{\mathrm{b}}$ \\ ${ }^{a}$ Departement of Sains Informasi Geografi 1, Jl. Kaliurang, Sekip Utara, Bulaksumur \\ Sinduadi Sleman 1, retnadih@ugm.ac.id 1 \\ ${ }^{\mathrm{b}}$ Departement of Sains Informasi Geografi 2, Jl. Kaliurang, Sekip Utara, Bulaksumur \\ Sinduadi Sleman 2, adistina.lailia.f@mail.ugm.ac.id 2
}

\begin{abstract}
Information on the latest land cover can be obtained from remote sensing data processing, but many do still use optical imagery. In fact, Indonesia is the next country tropical so that the possibility of disrupted cloud cover throughout the year is enormous. Therefore, it is necessary that imagery can penetrate the cloud cover of the radar image. Behind the excess, there is a weakness of radar imagery is a salt and paper disorder that appears bitnik-black and white spots on imagery. This Salt and paper can have a pixel value that is therefore less precise when a pixel-based classification is performed. It is necessary to do a classification that not only considers the pixel value of object-based classification. This research aims to segment objects in the form of land cover and calculate the accuracy of the segmentation results.

This research was conducted using a radar image, namely Citra Sentinel- $1 \mathrm{~A}$ with $10 \mathrm{~m} \times 10 \mathrm{~m}$ resolution. The segmentation process carried out using a multiresolution segmentation algorithm. Based on the results of the study, the best segmentation has an input channel parameter weight of $1,0.5,1$, output parameter weight 25 , shape parameter weight 0.3 and compactness parameter weight 0.9 . The value of segmentation accuracy produced by considering five parameters in the shape of oversegmentation (OSeg), undersegmentation (USeg), root mean square error (D), area fit index (AFI), and quality rate (Qr) is $57 \%$. Low accuracy value because radar images focus on object morphology in the shape of altitude and surface conditions. Whereas in a land cover the object's morphology can vary and surface roughness can vary.
\end{abstract}

Keywords: land cover, radar image, Sentinel-1A, object-based classification, multiresolution segmentation

\section{INTRODUCTION}

The cover of land according to Turner et al (1995, in Briassoulis, 2000) is the biological condition of the Earth's surface. Land cover is a condition or condition of land surface such as cropland, forest and forests, while Moser (1996, in Briassoulis, 2000) defines the cover of land refers to the type or type of vegetation that Cover the expanded surface of the land so it includes man-made structures such as buildings and other aspects of the physical environment.

One of the causes of land cover change is the increase of population. The increasing number of people in a place will have an impact on rising changes in land cover. The change of land cover has an impact on the environment both positive and negative. In order to minimize the adverse effects that may occur, the change of land cover must be controlled for the development of the region in a better direction. Therefore, it takes information about the land cover that is continuously updated as a basis for decision making and planning of a region. Therefore it takes technology that can map this dynamic land cover. According to Sampurno (2016) Remote sensing is an effective means to map the land cover spatially more efficiently than in conventional ways.

Extraction of information using SAR data that is often done still uses pixel-based extraction. Even though SAR data has speckle noise that can affect pixel values when pixel-based classification is performed. According to Sarjani et al., (2017), one of the characteristics of SAR images is the emergence of speckle 
noise, which appears as the texture of dark bright spots that are randomly distributed in the image. Speckle noise arises due to variations in the intensity of pixels, and this variation is considered a pattern of noise on SAR data. Speckle noise in SAR data provides difficulties in the process of image interpretation and analysis of SAR data, but it can also reduce the effectiveness of image segmentation in the SAR data (Putra, P.P, et al., 2015).

Over time and the development of science emerged extraction methods that did not only consider spectral aspects, namely object-based classification. Object-based classification is a classification process approach that does not only consider spectral aspects or information contained in one pixel but also considers the spatial aspects of objects.

In this study object-based classification was carried out for mapping land cover. Land cover is a physical appearance on the surface of the earth. Information about land cover is very important because it can be used for modeling and understanding phenomena that occur on the surface of the earth (Sampurno et al., 2016). The purpose of this study is to segment and calculate the accuracy of the segmentation.

\section{METHODOLOGY}

The image used is Sentinel-1A Image which is used to have the acquisition of IW (Interferometic Wide) mode GRDH (Ground Range Detected High) mode. IW or Interferometic Wide Swath is the main observation method on land with a spatial resolution of $5 \mathrm{~m} \times 20 \mathrm{~m}$. The Ground Range Detected High (GRDH) can produce a combination of recording width of $250 \mathrm{~km}$ with medium spatial resolution (Azimuth $\mathrm{x}$ resolution Range: $22 \mathrm{x}$ $20 \mathrm{~m})$.

Research location is located in part of Banguntapan village and Baturetno Village, District Banguntapan Bantul Regency of Special region of Yogyakarta, in $434136-434864 \mathrm{mT}$ and $9137520-913860 \mathrm{mU}$. The reason for this study area is due to its flat topography conditions so that Perbedaanketinggian does not affect radar image classification and the location of the study area has varied land cover variations. The study Area has a extention of about $615704.36 \mathrm{~m}^{2}$

The image used is geometrically corrected, and radiometrically corrected. Corrected image, less speckle interference with filtering technique. The filter used is a lee filter to soften speckle noise in the image by maintaining image sharpness and detail while reducing noise in the image. Then the radar intensity conversion is carried out in the form of a digital number that is linear to the decibell (dB) scale. To make it easier to do object-based classification a composite process is carried out. This composite image is done to facilitate visual observation. Composite imagery utilizes a combination of polarization from Sentinel- $1 \mathrm{~A}$ namely VV and VH on figure 1.

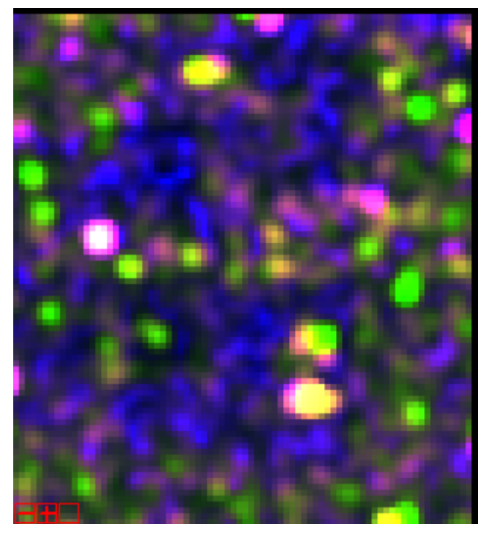

Figure 1. Composite imagery.

Object-based classification method is based on the process of image segmentation in a homogeneous area using shapes, textures, and contexts related to the pattern so that it becomes a more advanced basis for image analysis (Marpu, 2009). The segmentation method used is multiresolution segmentation. According to Wu et al., (2010) the accuracy test on object-based classification is not only in the thematic categories of 
objects but also to test the spatial accuracy of object boundaries compared to reference maps. To find out this, a quantitative accuracy test can be carried out by taking into account five parameters of segmentation accuracy. The five parameters for calculating segmentation accuracy are oversegmentation (OSeg), undersegmentation (USeg), root mean square error (D), area fit index (AFI), and quality rate (Qr). This segmentation accuracy test calculation is based on reference cover maps on figure 2 that have been made through field surveys. The reference map produces five classes of land cover.

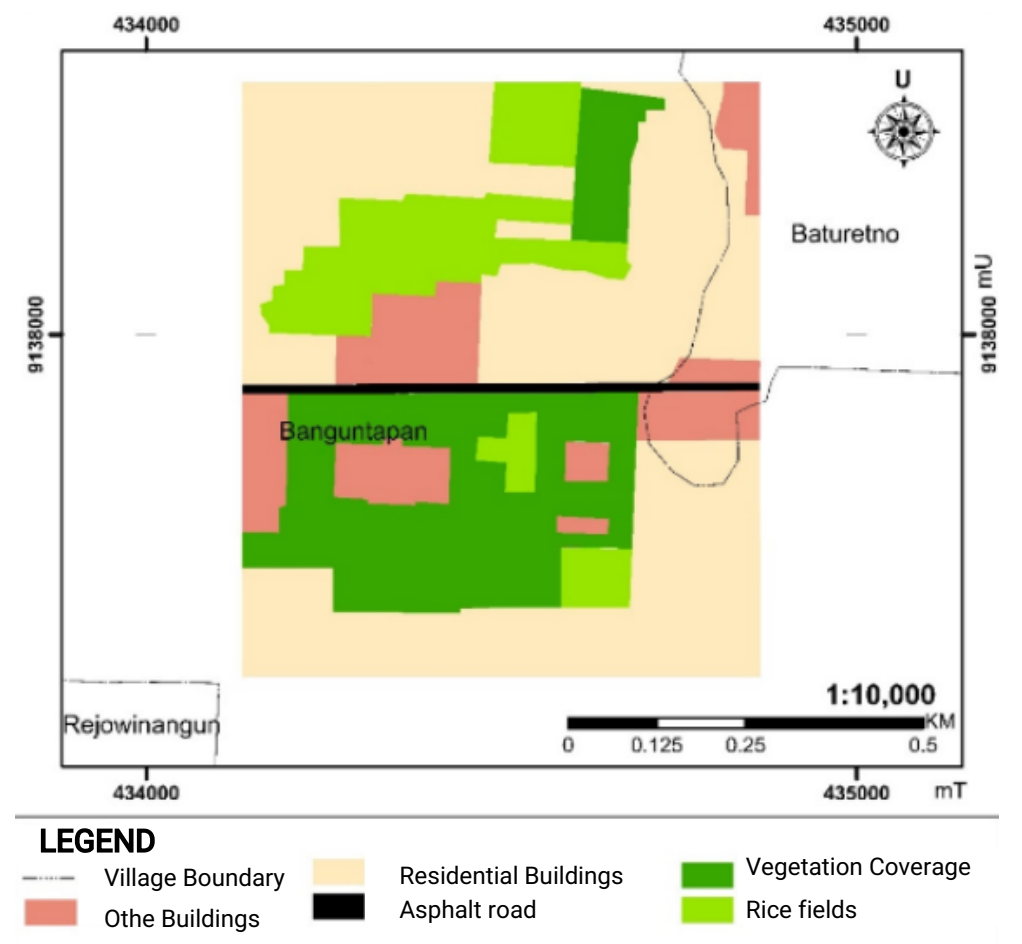

Figure 2. Reference Map.

\section{RESULT}

The segmentation algorithm used in this research is a multiresolution algorithm segmenting. The multiresolution algorithm of segmentation considers several parameters there are the weight of the input channel, the output weight (scale) and the homogenity consisting of a shape and color parameters (colour) and compactness and smoothness. This segmentation is carried out trial and error in weight giving each to get a good segment.

The input channel parameter means giving more weight to the more dominant layer or channel. The selection of the dominant layer is influenced by sensitivity to objects. Where VV polarization is sensitive to ground objects, the VH Polariasi and the synthetic band VH/VV are sensitive to vegetation objects. On the first channel is VH polarization, on the second channel is filled by VV polarization while on the third channel is filled by the synthetic band $\mathrm{VH} / \mathrm{VH}$.

Scales are parameters that set the minimum number of pixels in the segmentation results. The amount of weight in this parameter affects the size of the resulting segment. The bigger the weight, the more pixels you enter in a polygon, the larger the size or breadth of the segment. If the resulting segment is too large it will likely be an undersegmentation where in one segment consists of more than one object. In contrast, when the resulting segment is too small there is a possibility of oversegmentation where one object is divided into several segments.

The shape and color parameters are a unit of opposite value. The Total weight of the shape and color 
parameters is 1 , if the shape has a weight of 0.4 then the weight of the color parameter is automatically 0.6 . However, the weight value of a shape or color parameter should not be more than 0.9. Segmentation results are sprinkled with reference maps to make it easier to eliminate segments to continue to the next stage. Segmentation results are overlayed with reference maps to make it easier to eliminate segments to not proceed to the next stage.

The compctness and smoothness are one with the total weight of 1 , the same as the shape and color parameters. Suppose if the solidarity is given a value of 0.2 then automatically the smoothness will have a value of 0.8 . The weighting of these parameters depends on the commistness of the object in the field. An object called Compact is an object whose object has a distance between the center point and the edge of the object almost the same as the square, rectangle or circle.

Based on a reference map used that the resulting land cover polygons have a fairly orderly shape resembling a square, and a rectangle. Based on the reason, the simulation carried out at this level uses greater compresdity weights of $0.5,0.6,0.7,0.8$, and 0.9 . The simulation is applied to segments with input channel weights of $1,0.5,1$ with output 25 and the weight of parameters $0.5,0.4$ and 03 . There are 15 simulation results in figure 3 and figure 4.
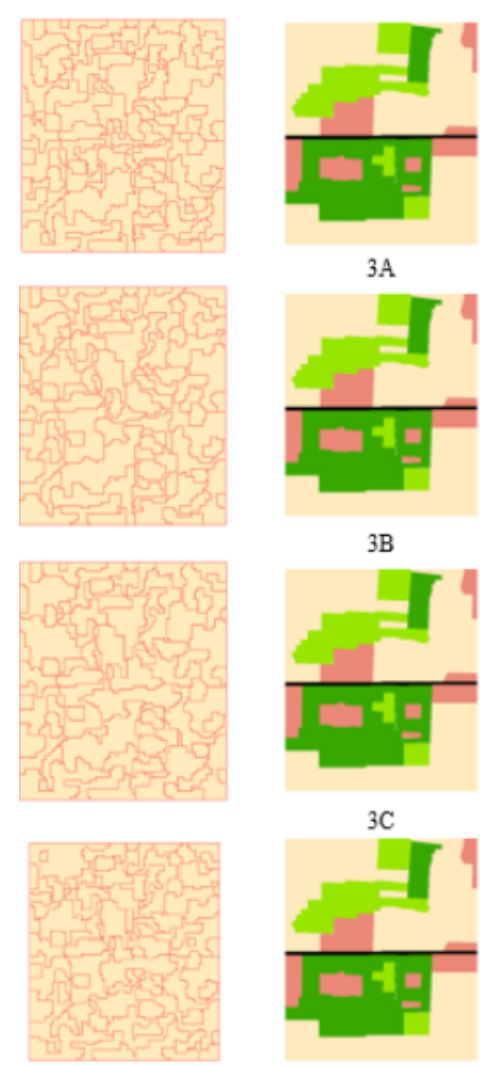

3 A

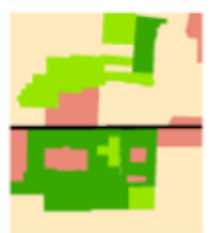

3B

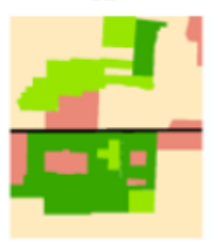

$3 \mathrm{C}$

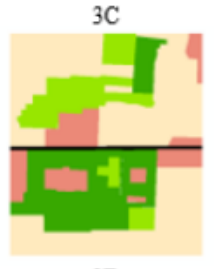

3D
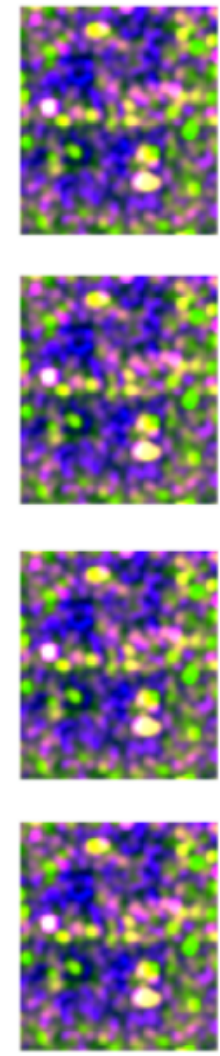
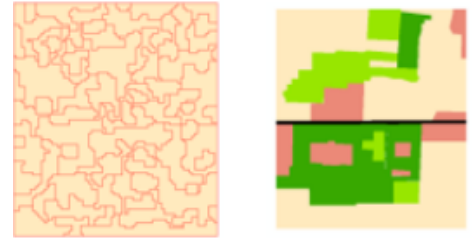

$4 \mathrm{D}$
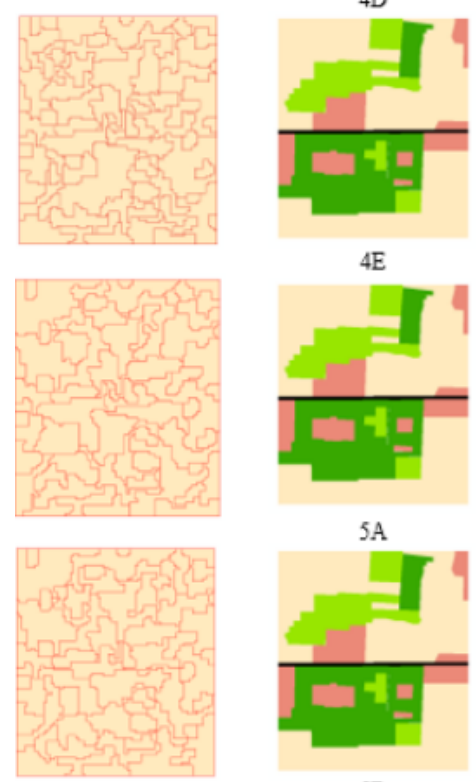

$4 \mathrm{E}$

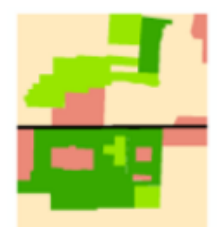

$5 \mathrm{~A}$

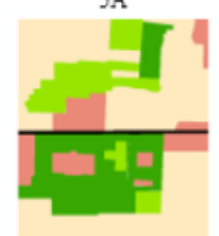

$5 \mathrm{~B}$
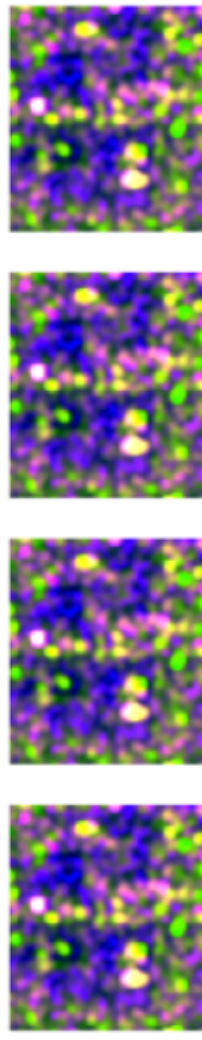

Figure 3. The result of segmentastion simulation
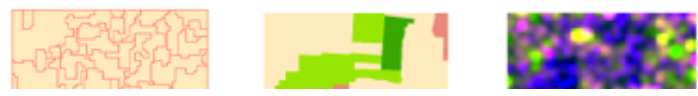

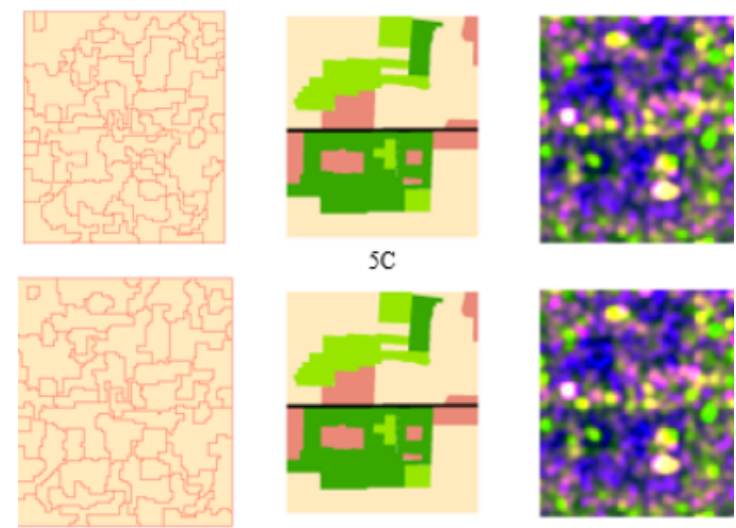

$5 \mathrm{C}$

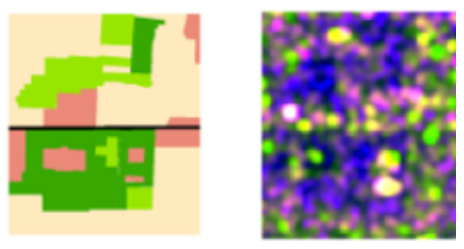

$5 \mathrm{D}$
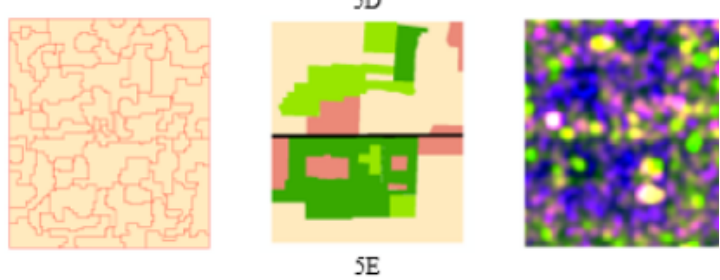

Figure 4. The result of segmentastion simulation

Segmentation accuracy tests are conducted to determine the accuracy value generated by 15 segments of simulated results that are executed. The accuracy test performed is a quantitative accuracy test with five calculation parameters. Five parameters to calculate segmentation accuracy are oversegmentation (OSeg), Undersegmentation (USeg), root means fault square (D), Fit Index (AFI) area, and quality Rate (QR). Oversegmentation (OSEG) occurs when the visit efficacy is in a segment but efficacy to several segments or segmentation of flavors on a single visit. The opposite is undersegmentation (USEG) which cannot distinguish different visit. This permissible is inserted in different segments, it does not dough. Error oversegmentation does not fully affect the outcome of poor classification because this error can be addressed through a strategy of setting a good rule before the classification process (Syarif, 2017).

The calculation of segmentation accuracy test involves the area of the segments resulting from 15 simulations of each land cover class. Calculations are differentiated into each land cover to determine the capability of Citra Sentinel-1A with the compossii VH, VV, VH/VH best in segmenting the land cover object. The classification of land cover produced only four land cover, namely rice fields, vegetation coverage, residential buildings and other buildings. This is because segmentation and imagery used are not able to distinguish asphalt roads. Based on these results it can be noted that in this research the cover of a land that is easily distinguished is the residential building. Because the residential buildings in the study area have a uniform height of about three to four meters with a similar texture. While the vegetation coverage has a low accuracy of the segment due to the vegetation cover is not uniform both in height, type and texture. It is very influential because the imagery used is a radar image, where the radar image works by sending energy that will be recorded response of such energy return as the response of the object.

The best segmentation by calculation is segmentation with the input channel weight is $1,0.5,1$. The scale weight is 25 , the weight of the shape parameters is 0.3 and the weight of the parameters of compactness is 0.9 . Accuracy obtained by 0.57987 or $57,987 \%$. The result of best segmentation on figure 5 . 


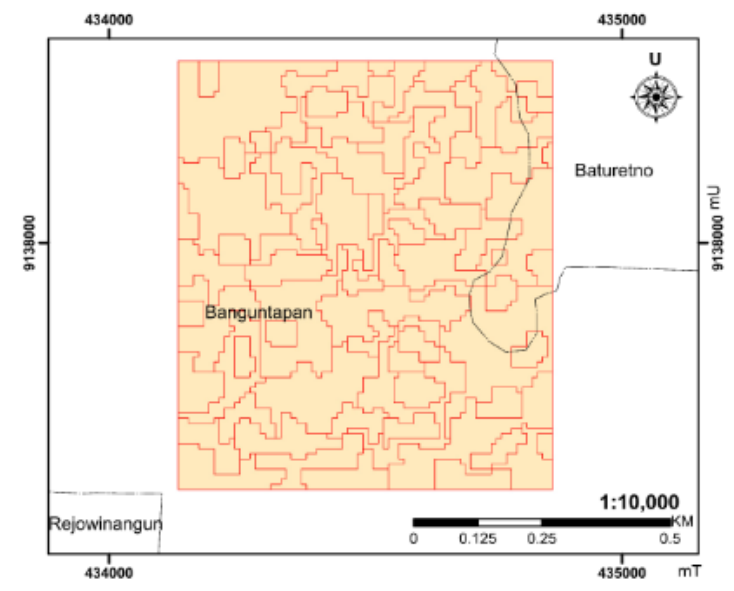

Figure 5. Segmentation Map.

\section{CONCLUSION}

Segmentation is done using multiresolution algorithms. The best segmentation has an input channel parameter weight of $1,0.5,1$, output parameter weight 25 , shape parameter weight 0.3 and compactness parameter weight 0.9 . The resulting segmentation accuracy value is $57 \%$.

\section{REFERENCES}

[1] Briassoulis, H., \& G. Lesvos. 2000. Analysis of Land Use Change: Theoretical and Modeling Approaches. The Web Book of Regional Science. Regional Research Institute. West Virginia University. Morgantown. WV. USA

[2] Marpu, P., Geographic object-based image analysis, Thesis (PhD). The Faculty of Geosciences, Geoengineering and Mining of the Technische Universitat Bergakademie, Freiberg, Germany, (2009)

[3] Putra, P.A., Prasetyo, Y., \& Haniah., Vegetation cover classification using polarimetric decomposition method ,Jurnal Geodesi Undip, (2015)

[4] Sampurno, M. R., \& Thoriq, A., Land cover Classification using image Landsat 8 Operational Land Imager (OLI) in Sumedang District, Jurnal Teknotan Vol. 10 No. 2, (2016)

[5] Sarjani, F., Sumantyo, J.T.A., \& Yohandri., Image Processing Satellite Alos Palsar using Method Polarimetry for Classifications of Land on Padang City Area. Eksakta Vol. 18 No. Jurnal Teknotan, 10(2), 61-70, (2017)

[6] Syarif, Akbar Muammar., Geospatial Object Based Image Analysis Small Format Aerial Photographs for Detailed Scale Cover Land Classification, Yogyakarta, Universitas Gadjah Mada, (2017)

[7] Wu, Zhacong., Yi, Lina., \& Zhang, Guifeng., Object-oriented Remote Sensed Image Classification Accuracy Assesment, Accuracy 2010 Symposium, July 20-23, Leicester, UK, (2010) 